\title{
Optimal initial cell density that yields the highest number of primary synovial mesenchymal stem cells in a clinical setting
}

\section{Kiyotaka Horiuchi}

Tokyo Medical and Dental University

\section{Mitsuru Mizuno}

Tokyo Medical and Dental University

\section{Hisako Katano}

Tokyo Medical and Dental University

\section{Kentaro Endo}

Tokyo Medical and Dental University

\section{Nobutale Ozeki}

Tokyo Medical and Dental University

\section{Kunikazu Tsuji}

Tokyo Medical and Dental University

\section{Hideyuki Koga}

Tokyo Medical and Dental University

Ichiro Sekiya ( $\square$ sekiya.arm@tmd.ac.jp)

Tokyo Medical and Dental University https://orcid.org/0000-0002-6331-722X

\section{Research}

Keywords: mesenchymal stem cell, synovium, initial cell density, primary cell, human serum

Posted Date: April 9th, 2020

DOI: https://doi.org/10.21203/rs.3.rs-21533/v1

License: (1) (1) This work is licensed under a Creative Commons Attribution 4.0 International License. Read Full License 


\section{Abstract}

Background Synovial mesenchymal stem cell (MSC) transplantation improved clinical outcomes in knees with cartilage defects and after repairs of degenerative torn menisci. For these, nucleated cells were cultured with $10 \%$ autologous serum for 14 days. Importantly, nucleated cell number and serum volume practically varied by patient, and initial cell density and dish number affected yield/donor. Our purpose was to examine the effect of plating density within range in clinical studies on fold increase and to estimate the MSC yield/donor, which are affected by the nucleated cell number and serum volume.

Methods We obtained the data of the autologous serum volume, nucleated cell number, and initial plating cell density from 10 patients who participated in our previous clinical studies. Experimentally, synovial nucleated cells harvested from three patients with osteoarthritis during total knee arthroplasty were cultured with $10 \%$ mixed allogenic human serum for 14 days to examine the effect of initial cell density on fold increase. We used both our previous clinical data and our current experimental data to predict the yields of synovial MSCs in nine cases within the range of clinical studies.

Results In the clinical studies, collected serum ranged between 87 and $186 \mathrm{ml}$, harvested nucleated cells ranged between 6.2 and 23 million, and the top five total MSC yields were obtained from donors when the initial plating cell density ranged from 919 to 1905 cells/cm 2 . Experimentally, fold increase significantly decreased between 700 and 1,900 cells/cm 2 . In cases where the cell number was low and the serum volume was high, the estimated yield/donor decreased along with the initial density, while in cases where the cell number was high and the serum volume was low, the estimated yield/donor increased along with the initial density. In cases both where some nucleated cells were discarded at low density and no cells were discarded at high density, the maximum yield/donor were obtained when the initial density was the lowest density that does not discard cells.

Conclusions There was an optimal initial density that yields the highest number of primary MSCs in a clinical setting when cell numbers and human serum volumes are limited.

\section{Background}

Mesenchymal stem cells (MSCs) are an attractive cell source for use in regenerative medicine and cell therapy[1]. MSCs can be isolated from various adult mesenchymal tissues; MSCs derived from synovium are attractive for cartilage and meniscus diseases, due to their high proliferative ability in culture with human serum and their remarkable chondrogenic potential[2]. Arthroscopic transplantation of synovial MSCs improved clinical outcomes in knees with cartilage defects[3]. A combination of surgical repair and synovial MSC transplantation also improved clinical outcomes for a complex degenerative tear of the medial meniscus[4].

For these cell therapies, just after enzyme digestion, synovial nucleated cells are plated on a certain number of dishes and are cultured with $10 \%$ autologous human serum for 14 days. Important to remember is that the available number of nucleated cells and the serum volume can practically vary from 
patient to patient and that the initial plating cell density[5] and the dish number, which depends on the initial plating cell density, affect the yields (Fig. 1).

Transplantation of autologous synovial MSCs at passage 0 for cartilage and meniscus therapy requires as many cells as possible since the number of synovial MSCs adhering to the cartilage[6] and meniscus[7] correlated with the therapeutic effect of the cells on the cartilage and meniscus injuries. In some clinical cases, the number of cells for transplantation may be less than that specified in the protocol. The purpose of this study was to estimate total MSC yields from the fold increase obtained in this experiment in several patterns, dependent on the total synovial nucleated cell number and autologous serum volume within the range of clinical studies. This could determine the optimal initial cell density that would yield the highest number of primary synovial MSCs in a clinical setting when the initial cell number and the volume of human serum are limited. In certain cases, more MSCs may be finally obtained by discarding a part of the nucleated cells.

\section{Methods}

\section{Clinical studies}

We transplanted autologous synovial MSCs on the repaired degenerative torn meniscus[4] and injected them into knee joints with osteoarthritis. These clinical studies (PB3150002 and PB3160032) were approved by the certified special committee for regenerative medicine at the Tokyo Medical and Dental University (committee reference number: NA8140003) and were carried out in accordance with the Helsinki Declaration. For autologous serum, we planned to collect $350 \mathrm{~mL}$ of whole blood while monitoring the weight of the blood bag, but the amount of blood collected was finally adjusted according to patients' situations. Then the serum was separated with a Cellaid closed bag (JMS), and the autologous serum volume was measured with a pipette. During the operation for meniscal repair under arthroscopy, approximately 20 pieces of synovial tissue were collected and weighed. After digestion in a solution of Liberase (Roche Diagnostics, Mannheim, Germany), synovial nucleated cells were counted. The cells were plated in approximately $50 \times 150 \mathrm{~cm}^{2}$ dishes and were cultured with $10 \%$ autologous serum for 14 days. The primary synovial MSCs were harvested with TrypLE (Thermo Fisher Scientific) and were counted. Then the cells were suspended in $0.5 \mathrm{~mL}$ acetate Ringer's solution (Veen-3G; Kowa, Tokyo, Japan) and were transplanted (Fig. 2). The data of blood volume, serum volume, synovial tissue weight, nucleated cell number, initial plating cell density, and total synovial MSC yields from 10 patients were analyzed in this study.

\section{Collection of human serum}

The present study was approved by the Medical Research Ethics Committee of Tokyo Medical and Dental University (approval no. 2017-142), and all study subjects provided informed consent. Three hundred milliliters of fresh blood were collected from four healthy volunteers (20-24 years of age) using a closed 
bag system (JMS Co. Ltd., Hiroshima, Japan)[8]. The bag, containing glass beads, was shaken at room temperature for $30 \mathrm{~min}$, and then the serum was separated[9]. The serum was filtered through a $0.45 \mu \mathrm{m}$ nylon filter (Thermo Fisher Scientific, Waltham, MA, USA) and was stored at $-20{ }^{\circ} \mathrm{C}$ until use.

\section{Synovial MSCs}

Human synovial tissue was harvested from the suprapatellar pouch of the knee joints of three patients with osteoarthritis during total knee arthroplasty. Donor $\alpha, \beta$, $\gamma$ were all female, 58,85 , and 70 years of age. The synovial membrane was minced and digested in $5 \mathrm{mg}$ Liberase MNP-S GMP (Roche Diagnostics, Mannheim, Germany) in distilled water at $37^{\circ} \mathrm{C}$ for three hours. After digestion, the debris was removed by filtration through a $70 \mathrm{~mm}$ nylon filter (Greiner Bio-One $\mathrm{GmbH}$, Frickenhausen, Germany). The nucleated cells were counted via an automated cell counter (Luna-FL; Logos Biosystems, Annandale, VA, USA). Then the cells were plated in $60 \mathrm{~cm}^{2}$ culture dishes (Nalgen Nunc International, Rochester, NY) in a-minimum essential medium (a-MEM; Thermo Fisher Scientific) supplemented by $10 \%$ allogeneic human serum derived from healthy donors. They were cultured at $37^{\circ} \mathrm{C}$ in a humidified $\mathrm{CO}_{2}$ chamber (Astec Co. Ltd., Fukuoka, Japan) for 14 days. The primary synovial MSCs were harvested with $0.25 \%$ trypsin and $1 \mathrm{mM}$ ethylenediaminetetraacetic acid (Thermo Fisher Scientific, Inc) at $37^{\circ} \mathrm{C}$ for five minutes, and the cell numbers were counted.

\section{Colony formation and cell morphology}

One of the dishes was fixed by $4 \%$ paraformaldehyde and stained with $0.5 \%$ crystal violet (Sigma-Aldrich, St. Louis, MO) in methanol for five minutes to visualize the colonies. Cell morphology was observed with a microscope (BZ-X700, Keyence Co., Ltd., Osaka, Japan).

\section{Estimated total MSC yields/donor.}

Since $18 \mathrm{ml}$ of medium containing $10 \%$ serum is required for a $145 \mathrm{~cm}^{2}$ dish, $1.8 \mathrm{ml}$ of serum covers one $145 \mathrm{~cm}^{2}$ dish. If serum volume is $87 \mathrm{ml}$ (Donor 1 ), the nucleated cell number is 6.2 million, the initial cell density is 1,000 cells $/ \mathrm{cm}^{2}$, the average fold increase is 13.4 (Donor $\mathrm{\gamma}$ ), and the yield/145 $\mathrm{cm}^{2}$ dish is 1.9 million, then the total serum required becomes $\left[6.2\right.$ million (cells) $/ 1,000\left(\right.$ cells $\left./ \mathrm{cm}^{2}\right) / 145\left(\mathrm{~cm}^{2}\right) \times 1.8(\mathrm{ml})$ =] $77 \mathrm{ml}$, which is lower than $87 \mathrm{ml}$. Therefore, all nucleated cells can be plated, and the number of dishes to plate becomes 43 . Then the estimated total MSC yield/donor becomes $\left[1000 \mathrm{cells} / \mathrm{cm}^{2} \times 145 \mathrm{~cm}^{2} \times\right.$ $13.4 \times 43=] 83.5$ million.

If the serum volume is $87 \mathrm{ml}$ (Donor 1 ), the nucleated cell number is 6.2 million, the initial cell density is 500 cells $/ \mathrm{cm}^{2}$, the fold increase is 22.0 (Donor $\mathrm{y}$ ), and the yield $/ 145 \mathrm{~cm}^{2}$ dish is 1.6 million, the total 
serum required becomes [6.2 million (cells)/500 (cells/ $\left.\left.\mathrm{cm}^{2}\right) / 145\left(\mathrm{~cm}^{2}\right) \times 1.8(\mathrm{ml})=\right] 154 \mathrm{ml}$, which is higher than $87 \mathrm{ml}$. Therefore, the possible number of dishes to plate becomes 48 , and the remaining cells are discarded. Then the estimated total MSC yield/donor becomes $\left[500\right.$ cells $/ \mathrm{cm}^{2} \times 145 \mathrm{~cm}^{2} \times 22.0 \times 48$ =] 76.6 million.

\section{Statistical analysis}

To evaluate the effect of initial cell density on fold increase, the Jonckheere-Terpstra test for trend was performed in R (version 3.4.3, The R Foundation for Statistical Computing). A p-value of 0.05 was set as significant.

\section{Results}

\section{Distribution of blood and synovium in clinical studies.}

In our previous clinical studies on 10 patients, blood collected ranged between $210 \mathrm{ml}$ and $400 \mathrm{ml}$ (average $337 \mathrm{ml}$ ), and the serum collected ranged between $87 \mathrm{ml}$ and $186 \mathrm{ml}$ (average $146 \mathrm{ml}$ ) (Fig. 3A). The synovial tissue weight ranged between $500 \mathrm{mg}$ and $1482 \mathrm{mg}$ (average $968 \mathrm{mg}$ ), the synovial nucleated cell number ranged between 6.2 and 23 million cells (average 12 million cells), and the initial plating cell density ranged between $689 \mathrm{cells} / \mathrm{cm}^{2}$ and $2734 \mathrm{cells} / \mathrm{cm}^{2}$ (average $1334 \mathrm{cells} / \mathrm{cm}^{2}$ ) (Fig. 3B, C). The number of synovial nucleated cells per weight ranged between 0.5 million cells $/ 100 \mathrm{mg}$ and 2.1 million cells/100 mg (data not shown). Total MSC yields/donor ranged between 23 million and 77 million cells (average 49 million cells) (Fig. 3C). Among 10 donors, the top five total MSC yields were donors 10, $5,3,1$, and 4 . This was when the initial plating cell density ranged from $919 \mathrm{cells} / \mathrm{cm}^{2}$ to $1905 \mathrm{cells} / \mathrm{cm}^{2}$.

\section{Effects of plating density on the proliferation of synovial MSCs}

Focusing on the range in which the top five total MSC yields were obtained, the effects of the initial cell density on the harvested cell number/dish and fold increase were experimentally examined in detail. The harvested cell number/dish appeared to increase slightly up to $1,600 \mathrm{cells} / \mathrm{cm}^{2}$ in Donors a and $\beta$. The fold increase significantly decreased by an amount between 700 and $1,900 \mathrm{cells} / \mathrm{cm}^{2}$ in these donors (Fig. 4).

We further experimentally examined the effects of the initial cell density on the harvested cell number/dish and fold increase extending the range of the initial density. The harvested cell number/dish appeared to increase up to 3,500 cells $/ \mathrm{cm}^{2}$ in Donor $y$ (Fig. $5 \mathrm{~A}$ ). The fold increase significantly decreased by between 500 and 4,000 cells $/ \mathrm{cm}^{2}$ in this donor. The cell colonies were distinct at $500 \mathrm{cells} / \mathrm{cm}^{2}$ and became indistinct with a higher initial cell density (Fig. 5B). 


\section{Estimated total MSC yield/donor}

In a case where the nucleated cell number was 6.2 million (the lowest case in clinical studies), the estimated MSC yield/donor decreased along with the initial cell density in a case where the serum volume was $186 \mathrm{ml}$ (the highest case in clinical studies) (Fig. 6). In a case where the serum volume was $146 \mathrm{ml}$ (the average case in clinical studies) and $87 \mathrm{ml}$ (the lowest case in clinical studies), when plating at low density, some cells were discarded due to insufficient serum volume.

In a case where the nucleated cell number was 12 million (the average case in clinical studies), when plating at low density, some cells were discarded due to insufficient serum volume in all three cases of serum volume. The maximum MSC yield/donor was obtained at the highest plating density under conditions where some cells were discarded.

In a case where the nucleated cell number was 23 million (the highest case in clinical studies), some cells were discarded due to insufficient serum volume in cases where the serum volume was $186 \mathrm{ml}$ and 146 $\mathrm{ml}$, except when plating at high density. In a case where the serum volume was $87 \mathrm{ml}$, some cells were discarded at all plating densities, and estimated MSC yield/donor increased along with initial cell densities.

\section{Discussion}

In our previous clinical studies, the total serum volume varied by patient. There are three possible reasons for the variation in serum volume. First, the total blood volume varied. We planned to collect $350 \mathrm{~mL}$ of whole blood while monitoring the weight of the blood bag. From one patient, only $200 \mathrm{ml}$ blood was collected, because her blood vessels were technically too thin to collect any more blood. From another patient, $400 \mathrm{ml}$ blood was collected, because his meniscus was extensively injured, he was healthy enough except for the meniscus, and we thought it was better to prepare more MSCs than usual for treatment. Second, even if we collected the same amount of blood, the amount of serum is affected by some factors, including the difference in hematocrit. Third, we isolated serum using a closed bag system (Cellaid), the bag containing blood with glass beads was shaken at $20^{\circ} \mathrm{C}$ for 30 minutes, and then the serum was separated. During this process, the prepared serum volume might vary.

In our previous clinical studies, the total synovial nucleated cell number also varied by patient. There are three possible reasons for the synovial nucleated cell number. First, the synovial tissue weight varied. We collected approximately 20 pieces of synovial tissue under arthroscopy, put them into a tube, and after the harvest of synovium was completed, we weighed it in another room outside the operating room. The synovial weight we expected was not accurate. Second, the number of synovial nucleated cells per weight depends on the donor. According to our study, synovium containing many fibrous components has more cells than synovium containing many adipose components[10]. Third, we minced the synovium, digested 
it with enzyme, filtered it, and counted the synovial nucleated cell number. During such a process, the prepared synovial nucleated cell number might vary.

Initial cell plating density affects the proliferation potential of MSCs. In our recent report, we plated the synovial nucleated cells at $10^{3}, 10^{4}$, or $10^{5}$ cells $/ 60 \mathrm{~cm}^{2}$ dish and cultured them for 14 days. The fold increase was negatively related to plating density, whereas the total number of cells/dish was positively related to plating density[5]. In our current study, we did similar experiments at densities of every 300 cells $/ 60 \mathrm{~cm}^{2}$ dish rather than every 10 times that many cells $/ 60 \mathrm{~cm}^{2}$ dish, and similar results were obtained.

We used our previous clinical data and our current experimental data to predict the yields of synovial MSCs in nine cases when the human serum volume was minimum, average, and maximum and when the initial numbers of nucleated cells were minimum, average, and maximum (Fig. 6). Generally, in cases where the nucleated cell number was low and the serum volume was high, the estimated MSC yield/donor decreased along with the initial plating density, while in cases where the nucleated cell number was high and the serum volume was low, the estimated MSC yield/donor increased along with the initial plating density. In cases both where some nucleated cells were discarded at low initial cell density and no nucleated cells were discarded at high cell density, the maximum MSC yield/donor were obtained when the initial cell density was the lowest cell density that does not discard cells.

In clinical situations, there should be the best combination of plating density and dish number to obtain the maximum MSC yield/donor. In a case where the serum volume is sufficient, the maximum MSC yield/donor is obtained when the initial cell density is the lowest within the range. In a case where the serum volume is moderate, the maximum MSC yield/donor is obtained when the initial cell density will be the lowest cell density that does not discard cells. In a case where the serum volume is low, the maximum MSC yield/donor is obtained when the initial cell density is the highest within the range (Fig. 7).

In this study, we identified an optimal initial cell density for harvesting the highest number of primary synovial MSCs in a clinical setting under conditions of limited cell numbers and human serum volume. In clinical situations, the use of passage 0 synovial MSCs could be valuable in reducing the effort required by replating as well as in preventing the possible risks related to chromosomal abnormalities[11, 12]. This result is important for other MSCs derived from bone marrow[13, 14], adipose tissues[15], and other mesenchymal tissues when the MSCs are cultured with human serum.

We propose three limitations. First, for this experimental data, synovial MSCs were cultured with allogeneic human serum, because it was difficult to collect both human synovium and serum from the same donors, for ethical reasons. Results using autologous serum may differ from those performed using allogeneic serum. Second, we estimated MSC yield/donor from the fold increase obtained in this experiment. However, we did not take into account that the proliferative capacity of MSCs varied between donors. Third, this study did not consider chondrocyte differentiation potential. In our recent report, the cartilage pellet weight was negatively related to the initial plating density[5]. 


\section{Conclusions}

In conclusion, an optimal initial cell density exists for harvesting the highest number of primary synovial MSCs in clinical settings when cell numbers and human serum volumes are limited.

\section{Abbreviations}

MSC

mesenchymal stem cell

a-MEM

Alpha minimum essential medium

\section{Declarations}

\section{Ethics approval and consent to participate}

These clinical studies (PB3150002 and PB3160032) were approved by the certified special committee for regenerative medicine at the Tokyo Medical and Dental University (committee reference number: NA8140003) and were carried out in accordance with the Helsinki Declaration.

\section{Consent for publication}

All authors consented for publication.

\section{Availability of data and materials}

All the data supporting the results can be found in this manuscript. Please contact the corresponding author with any additional data requests.

\section{Competing interests}

The authors declare no conflicts of interest.

\section{Funding}

Not applicable 


\section{Authors' contributions}

K.H. contributed to the conception and design, collection of data, analysis and interpretation of data, and manuscript writing. M.M. contributed to the conception and design, interpretation of data, and administrative support. H.Ka. and K.E. contributed to the conception and design and interpretation of data. K.T. and H.Ko. contributed to the interpretation of data. I.S. contributed to the conception and design, financial support, manuscript writing, and final approval of the manuscript.

\section{Acknowledgements}

We thank Ms. Mika Watanabe and Ms. Kimiko Takanashi for the management of our laboratory and Ellen Roider for English editing.

\section{Author's information}

\section{Affiliations}

Center for Stem Cell and Regenerative Medicine, Tokyo Medical and Dental University, Tokyo, Japan Kiyotaka Horiuchi, Mitsuru Mizuno, Hisako Katano, Kentaro Endo Nobutale Ozeki and Ichiro Sekiya Department of Cartilage Regeneration, Tokyo Medical and Dental University, Tokyo, Japan

Kunikazu Tsuji

Department of Joint Surgery and Sports Medicine, Tokyo Medical and Dental University, Tokyo, Japan Hideyuki Koga

\section{References}

1. Wang AT, Feng Y, Jia HH, Zhao M, Yu H. Application of mesenchymal stem cell therapy for the treatment of osteoarthritis of the knee: A concise review. World J Stem Cells. 2019;11(4):222-35. doi:.

2. Sakaguchi Y, Sekiya I, Yagishita K, Muneta T. Comparison of human stem cells derived from various mesenchymal tissues: superiority of synovium as a cell source. Arthritis Rheum. 2005;52(8):2521-9. doi:. 
3. Sekiya I, Muneta T, Horie M, Koga H. Arthroscopic Transplantation of Synovial Stem Cells Improves Clinical Outcomes in Knees With Cartilage Defects. Clin Orthop Relat Res. 2015;473(7):2316-26. doi:.

4. Sekiya I, Koga H, Otabe K, Nakagawa Y, Katano H, Ozeki N, et al. Additional Use of Synovial Mesenchymal Stem Cell Transplantation Following Surgical Repair of a Complex Degenerative Tear of the Medial Meniscus of the Knee: A Case Report. Cell Transplant. 2019;28(11):1445-54. doi:.

5. Nakamura K, Tsuji K, Mizuno M, Koga H, Muneta T, Sekiya I. Initial cell plating density affects properties of human primary synovial mesenchymal stem cells. J Orthop Res. 2019;37(6):1358-67. doi:.

6. Koga H, Shimaya M, Muneta T, Nimura A, Morito T, Hayashi M, et al. Local adherent technique for transplanting mesenchymal stem cells as a potential treatment of cartilage defect. Arthritis Res Ther. 2008;10(4):R84. doi:.

7. Mizuno K, Muneta T, Morito T, Ichinose S, Koga H, Nimura A, et al. Exogenous synovial stem cells adhere to defect of meniscus and differentiate into cartilage cells. J Med Dent Sci. 2008;55(1):10111.

8. Mizuno N, Shiba H, Ozeki Y, Mouri Y, Niitani M, Inui T, et al. Human autologous serum obtained using a completely closed bag system as a substitute for foetal calf serum in human mesenchymal stem cell cultures. Cell Biol Int. 2006;30(6):521-4. doi:.

9. Mizuno M, Katano H, Otabe K, Komori K, Matsumoto Y, Fujii S, et al. Platelet-derived growth factor (PDGF)-AA/AB in human serum are potential indicators of the proliferative capacity of human synovial mesenchymal stem cells. Stem Cell Res Ther. 2015;6:243. doi:.

10. Mochizuki T, Muneta T, Sakaguchi Y, Nimura A, Yokoyama A, Koga H, et al. Higher chondrogenic potential of fibrous synovium- and adipose synovium-derived cells compared with subcutaneous fatderived cells: distinguishing properties of mesenchymal stem cells in humans. Arthritis Rheum. 2006;54(3):843-53. doi:

11. Ermis A, Hopf T, Hanselmann R, Remberger K, Welter C, Dooley S, et al. Clonal chromosome aberrations in cell cultures of synovial tissue from patients with rheumatoid arthritis. Genes Chromosomes Cancer. 1993;6(4):232-4. doi:.

12. Ben-David U, Mayshar Y, Benvenisty N. Large-scale analysis reveals acquisition of lineage-specific chromosomal aberrations in human adult stem cells. Cell Stem Cell. 2011;9(2):97-102. doi:.

13. Kubo H, Takamura K, Nagaya N, Ohgushi $\mathrm{H}$. The effect of serum on the proliferation of bone marrowderived mesenchymal stem cells from aged donors and donors with or without chronic heart failure. J Tissue Eng Regen Med. 2018;12(1):e395-e7. doi:.

14. Fani N, Ziadlou R, Shahhoseini M, Baghaban Eslaminejad M. Comparative epigenetic influence of autologous versus fetal bovine serum on mesenchymal stem cells through in vitro osteogenic and adipogenic differentiation. Exp Cell Res. 2016;344(2):176-82. doi:.

15. Atashi F, Jaconi ME, Pittet-Cuenod B, Modarressi A. Autologous platelet-rich plasma: a biological supplement to enhance adipose-derived mesenchymal stem cell expansion. Tissue Eng Part C 


\section{Figures}

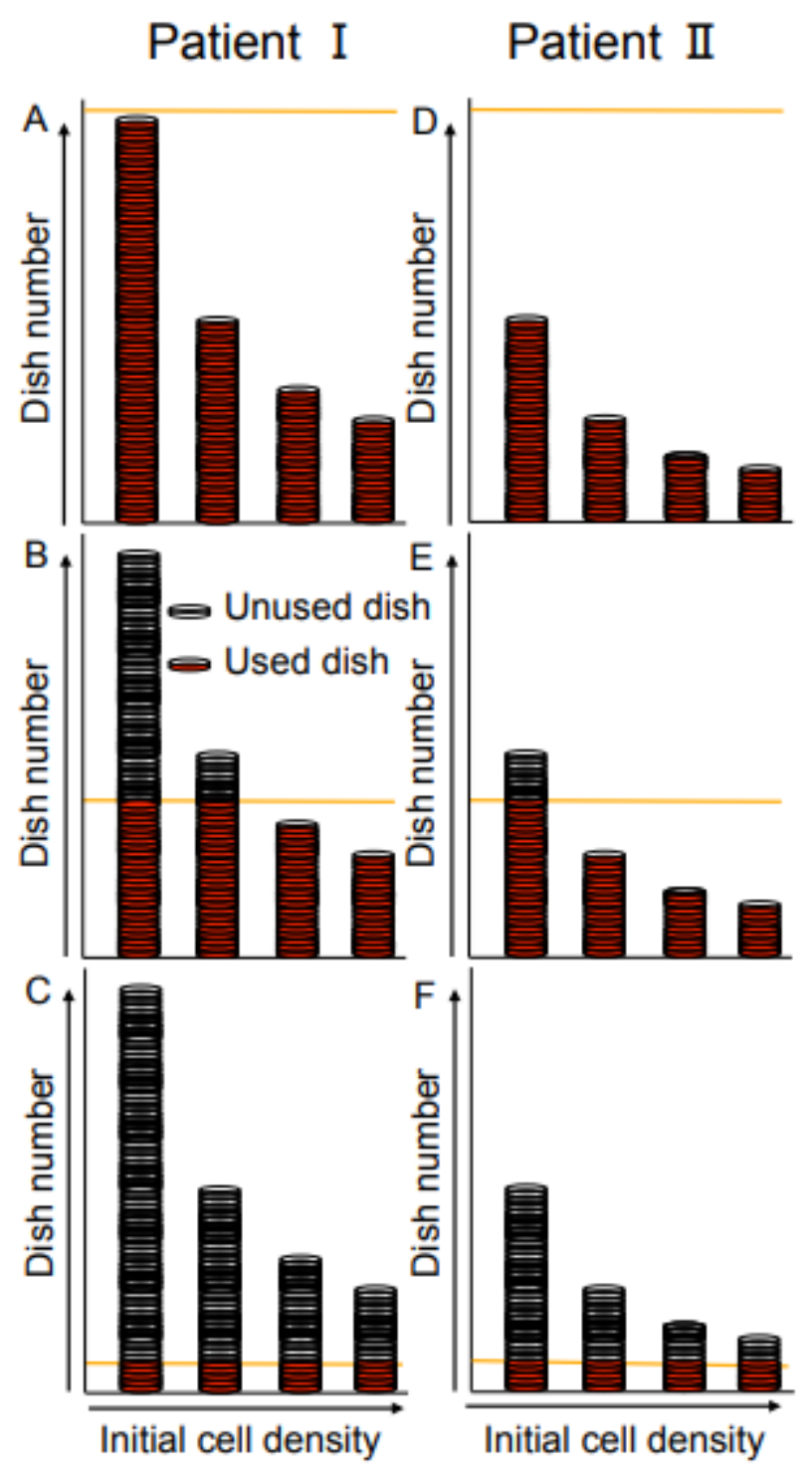

Figure 1

Background for this study. In our clinical situations, synovial nucleated cells just after enzyme digestion are plated on a certain number of dishes and cultured with $10 \%$ autologous human serum for 14 days to obtain a maximum number of primary autologous synovial MSCs. (A) If we have sufficient autologous serum, then the lower the initial cell density, the higher the number of dishes we can plate on. (B) If we have a limited amount of autologous serum, the number of dishes is limited, depending on the initial cell density. Below the orange line indicates the dishes used and above the orange line indicates the dishes unused. (C) If we have further limited autologous serum, the number of dishes is also further limited. (D) In another patient, the lower the number of nucleated cells we can prepare, the lower the number of dishes we can plate on. (E) If we have a limited amount of autologous serum, the number of dishes is also 
limited, depending on the initial cell density. (F) If we have further limited autologous serum, the number of dishes is also further limited. According to nucleated cell number and autologous serum volume, the optimal initial cell density should be decided.

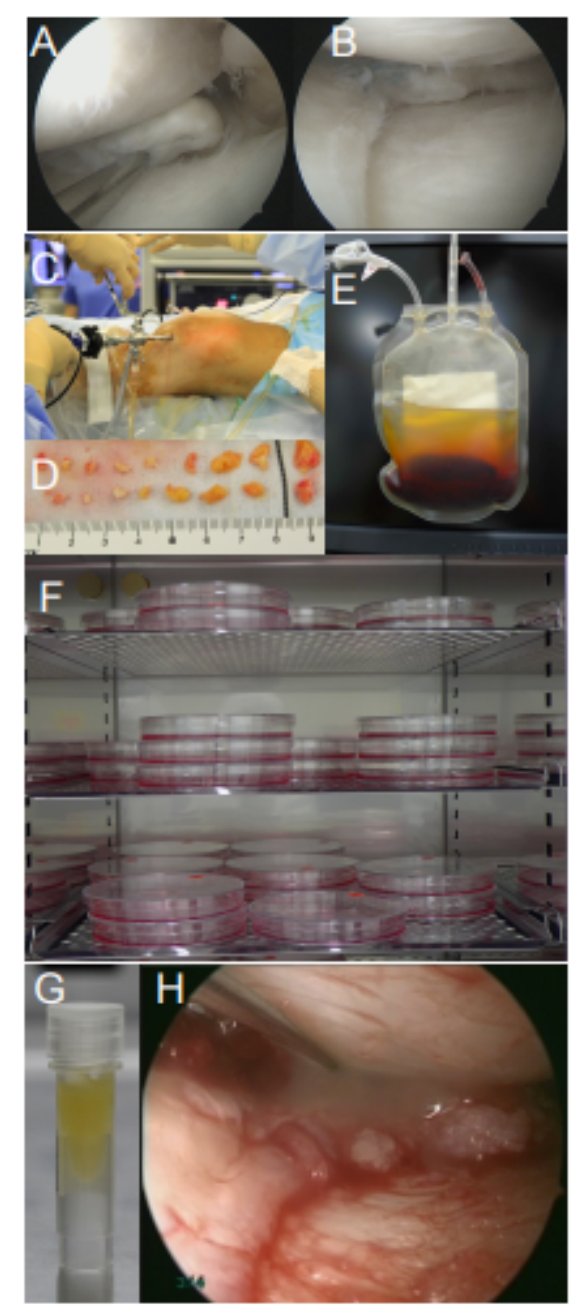

\section{Figure 2}

Procedure for transplantation of synovial MSCs onto the repaired meniscus. For degenerative torn meniscus (A), meniscal repair is performed (B). With a pituitary rongeur (C), approximately 20 pieces of synovial tissue are harvested (D). $350 \mathrm{ml}$ of autologous blood is harvested, and autologous serum is separated (E). Primary autologous synovial MSCs are cultured with $10 \%$ autologous serum for 14 days (F). Primary autologous synovial MSCs are suspended (G) and transplanted onto the repaired meniscus $(\mathrm{H})$. 
A

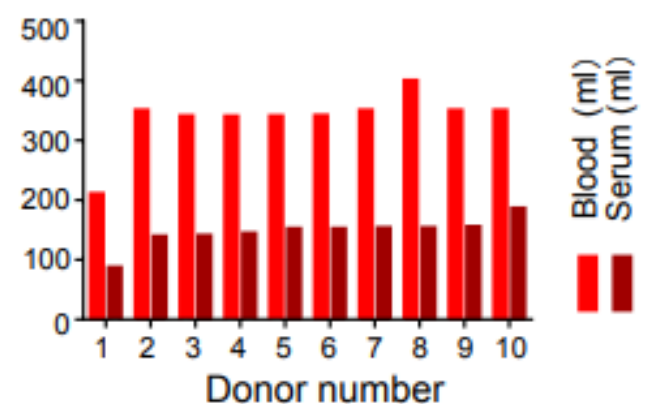

B
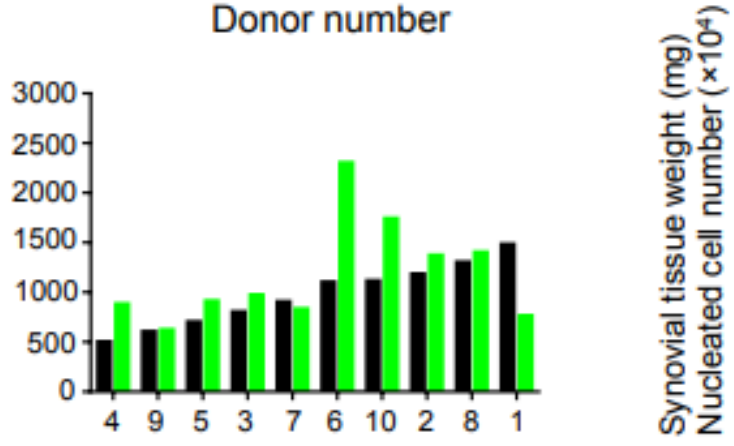

C

Donor number

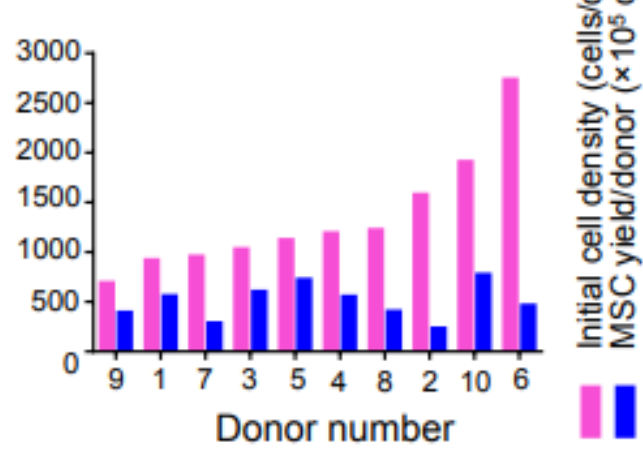

Figure 3

Distribution of blood and synovium derivatives from 10 patients in our previous clinical studies. (A) Blood volume and serum volume. Donor numbers were ordered in ascending serum volume. (B) Synovial tissue weight and nucleated cell number. (C) Initial cell density and MSC yields. 


\section{Donor a}
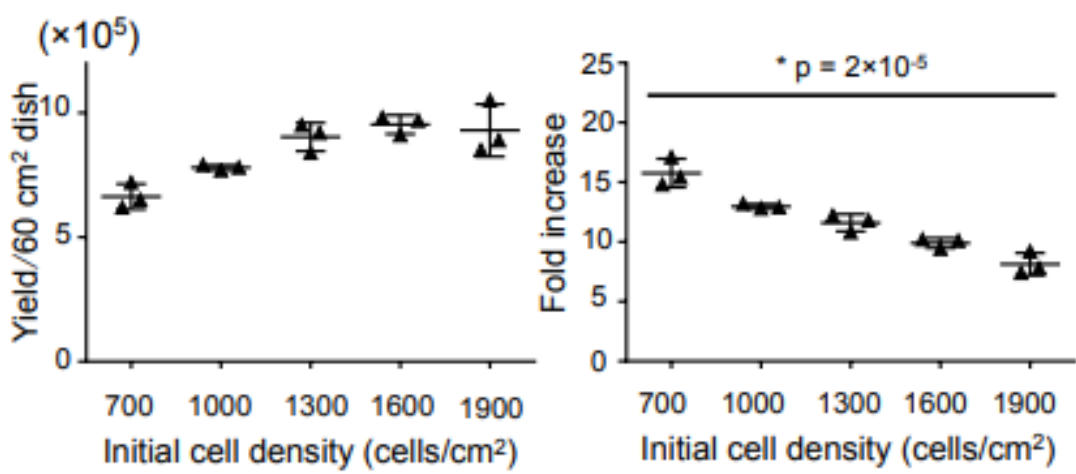

\section{Donor $\beta$}

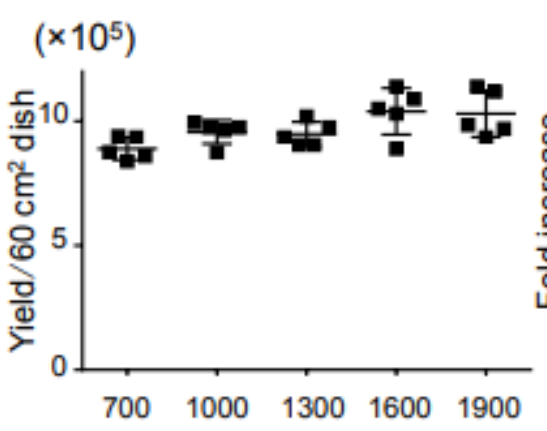

Initial cell density (cells $/ \mathrm{cm}^{2}$ )

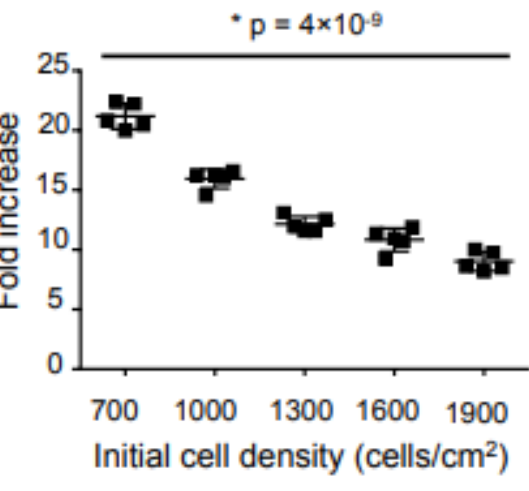

\section{Figure 4}

Effect of initial cell density on harvested cell number/dish and fold increase in primary synovial MSCs in this experimental study. Nucleated cells derived from synovium were plated at $700,1000,1300,1600$, or $1900 \mathrm{cell} / \mathrm{cm} 2$ in three $60 \mathrm{~cm} 2$ dishes and were cultured for 14 days in two donors. Average and SD are shown in addition to each plot. *; To evaluate the effect of initial cell density on fold increase, the Jonckheere-Terpstra test for trend was performed. 


\section{Donor $\mathrm{y}$}
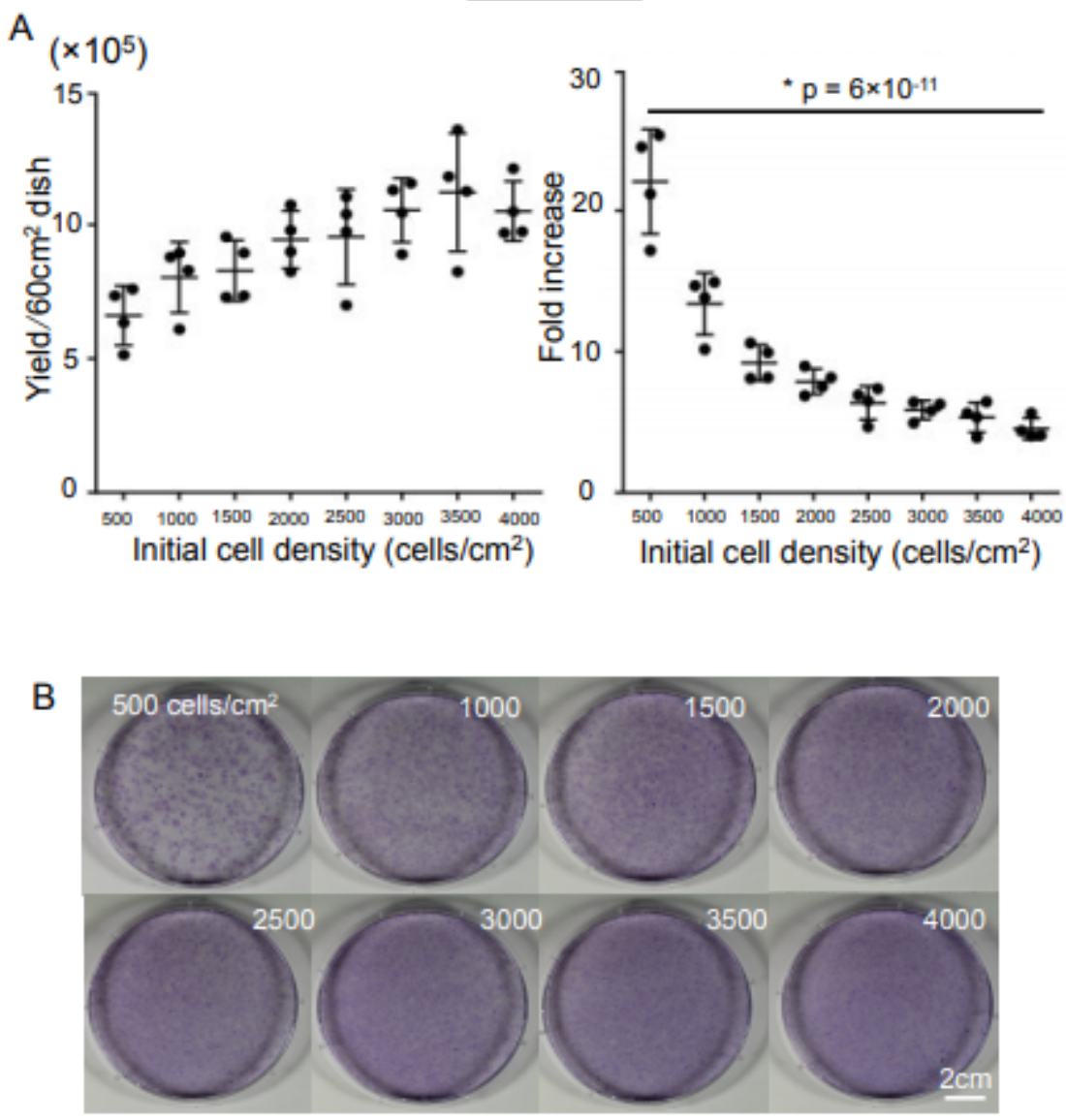

\section{Figure 5}

Effect of detailed initial cell density on fold increase and colony morphology in primary synovial MSCs in this experimental study. Nucleated cells derived from synovium were plated at 500, 1000, 1500, 2000, $2500,3000,3500$, and 4000 cells/cm2 dish in four $60 \mathrm{~cm} 2$ dishes and were cultured for 14 days. (A) Effect of initial cell density on harvested cell numbers/dish and fold increase in primary synovial MSCs. Average and SD are shown in addition to each plot. *; To evaluate the effect of initial cell density on fold increase, the Jonckheere-Terpstra test for trend was performed. (B) Representative colony formation of primary synovial MSCs stained with crystal violet. 


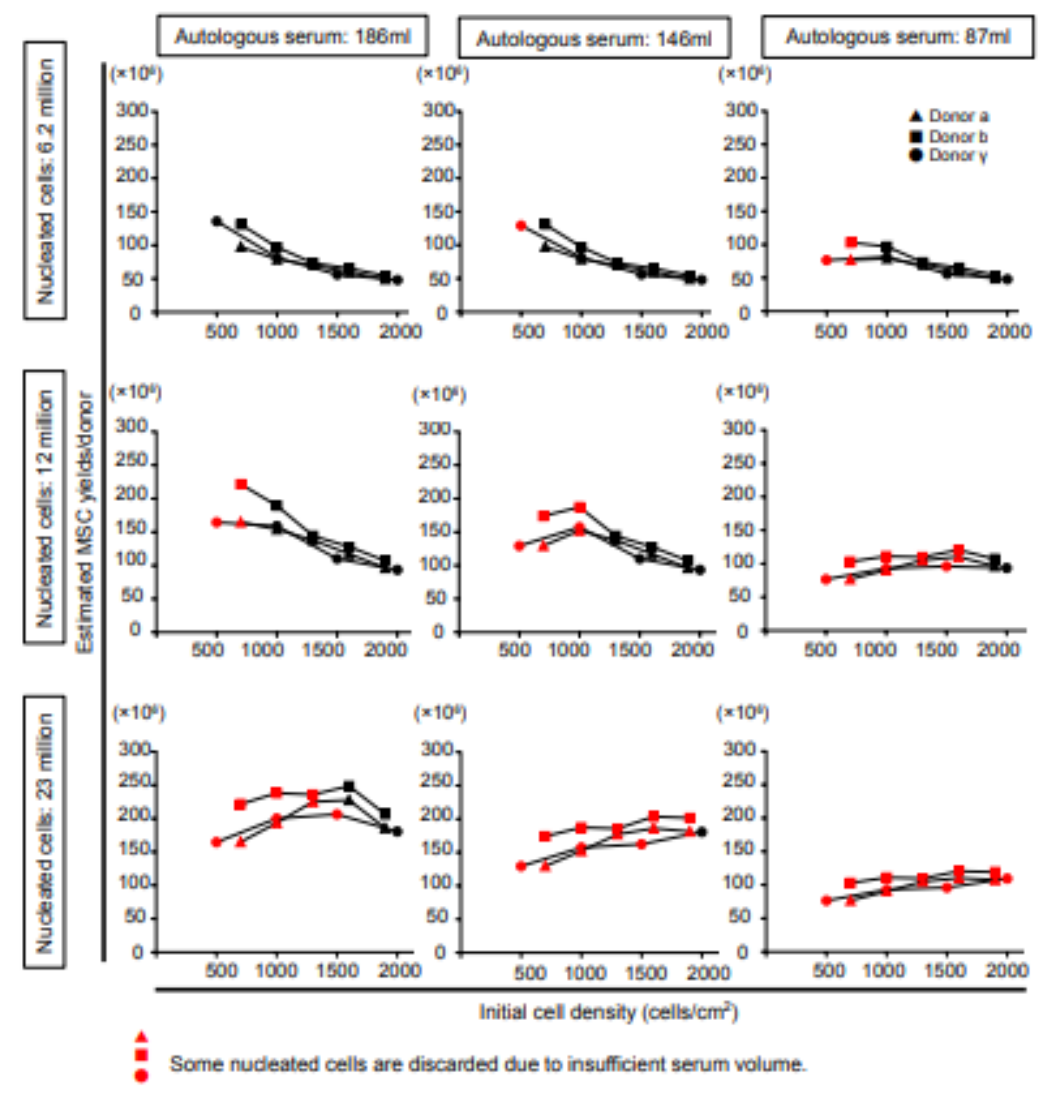

\section{Figure 6}

Estimated MSC yield/donor. MSC yield/donor was estimated from the fold increase obtained in this experiment in nine patterns of the minimum, average, and maximum of the total synovial nucleated cell numbers and the minimum, average, and maximum of the autologous human serum volume in the previous clinical studies. Red plots show the cases in which the remaining synovial nucleated cells were discarded. 


\section{A Sufficient serum volume}

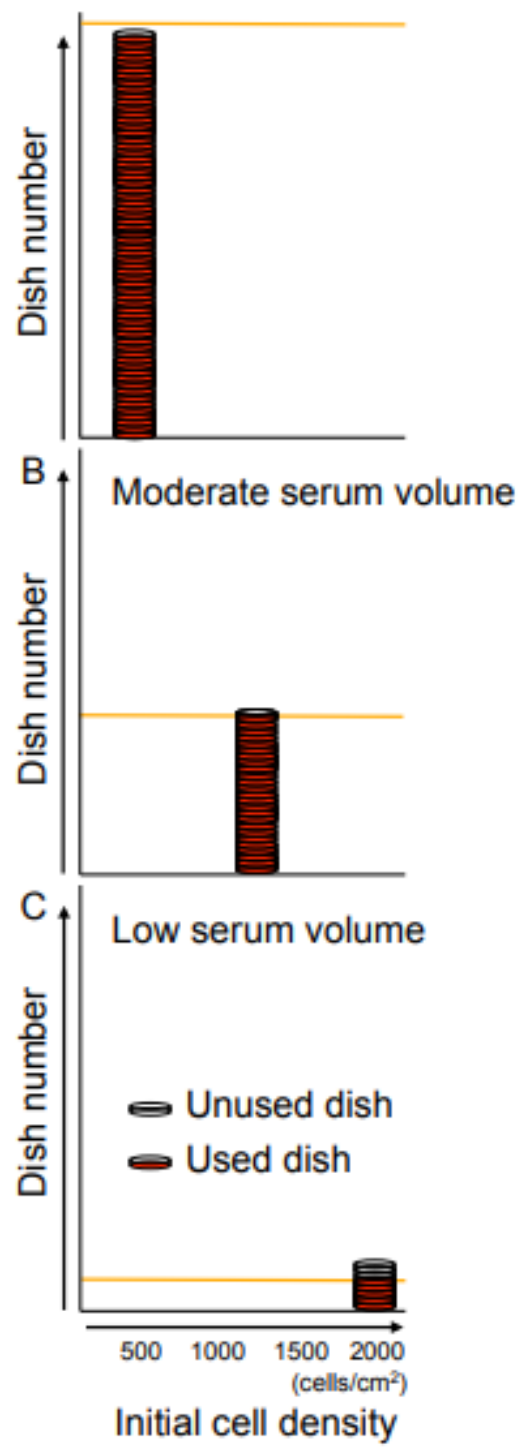

\section{Figure 7}

The optimal combination of initial cell density and dish number to obtain the maximum MSC yield/donor. (A) In a case where the serum volume is sufficient, the maximum MSC yield/donor is obtained when the initial cell density is the lowest within the range. (B) In a case where the serum volume is moderate, the maximum MSC yield/donor is obtained when the initial cell density will be the lowest cell density that does not discard cells. (C) In a case where the serum volume is low, the maximum MSC yield/donor is obtained when the initial cell density is the highest within the range, even if some cells are discarded. Below the orange line indicates the dishes used, and above the orange line indicates the dishes unused. 